\title{
Clinical decision-making and health-related quality of life during first-line and maintenance therapy in patients with advanced non-small cell lung cancer (NSCLC): findings from a real-world setting
}

\author{
Monika Sztankay ${ }^{1,2^{*}}$ (D) Johannes Maria Giesinger ${ }^{1}$, August Zabernigg ${ }^{3}$, Elisabeth Krempler ${ }^{1}$, Georg Pall ${ }^{4}$, \\ Wolfgang Hilbe ${ }^{5}$, Otto Burghuber ${ }^{6}$, Maximilian Hochmair ${ }^{6}$, Gerhard Rumpold ${ }^{1}$, Stephan Doering ${ }^{7}$ \\ and Bernhard Holzner ${ }^{1}$
}

\begin{abstract}
Background: Maintenance therapy (MT) with pemetrexed has been shown to improve overall and progression-free survival of patients with non-squamous non-small cell lung cancer (NSCLC), without impairing patients' healthrelated quality of life (HRQOL) substantially. Comprehensive data on HRQOL under real-life conditions are necessary to enable informed decision-making. This study aims to (1) assess HRQOL during first-line chemotherapy and subsequent MT and (2) record patients' and physicians' reasons leading to clinical decisions on MT.

Methods: Patients treated for NSCLC at three Austrian medical centres were included. HRQOL was assessed at every chemotherapy cycle using the EORTC QLQ-C30/+LC13 questionnaire. Semi-structured interviews were conducted before MT initiation and at the time of discontinuation to evaluate patients' and physicians' reasons for treatment decisions. Longitudinal QOL analysis was based on linear mixed models.

Results: Sixty-one (73\%) out of 84 patients were considered for MT. Thirty-six patients (43\%) received MT and 29 (35\%) discontinued therapy. Decisions on MT initiation (in 20 cases by the physician vs 4 by the patient) and discontinuation (19 vs 10) were mainly voiced by the physician. Treatment toxicity of first-line chemotherapy was the main reason for rejection of MT in patients with stable disease and was more often indicated by patients than clinicians. HRQOL data were collected from 83 patients at 422 assessment time points and indicated significantly lower symptom severity during MT compared with first-line therapy for nausea and vomiting $(p=0.006)$, sleep disturbances $(p<0.001)$, appetite loss $(p=0.043)$, constipation $(p=0.017)$ and chest pain $(p=0.022)$, and a deterioration in emotional functioning $(p=0.023)$ and cognitive functioning $(p=0.044)$ during MT. (Continued on next page)
\end{abstract}

\footnotetext{
* Correspondence: monika.sztankay@tirol-kliniken.at

${ }^{1}$ Department of Psychiatry, Psychotherapy \& Psychosomatics, Medical University of Innsbruck, Innsbruck, Austria

${ }^{2}$ Leopold-Franzens-University of Innsbruck, Innsbruck, Austria

Full list of author information is available at the end of the article
} 
(Continued from previous page)

Conclusions: Our results indicate that $\mathrm{HRQOL}$ and symptom burden improve between first-line treatment to MT in some respects, although some late toxicity persists. Discrepancies between patients' and physicians' perception of reasons for rejecting MT were evident. Thus, the integration of patient-reported outcomes, such as HRQOL, is required to enable shared decision-making and personalised healthcare based on mutual understanding of treatment objectives.

Keywords: Non-small cell lung cancer, Pemetrexed, Maintenance therapy, Decision making, Health-related quality of life

\section{Background}

Non-small cell lung cancer (NSCLC) accounts for $85 \%$ of all cases of lung cancer and causes the most cancer deaths worldwide $[1,2]$. More than $50 \%$ of NSCLC patients present with advanced disease at diagnosis, for which four to six cycles of platinum-based doublet chemotherapy is the standard first-line treatment [3]. Patients responding to first-line therapy with stable disease or a partial/complete response after cycle 4 are considered for subsequent maintenance therapy (MT), either with a new agent (i.e. switch $M T$ ) such as pemetrexed or erlotinib or with one of the first-line agents (i.e. continuation MT) such as pemetrexed or bevacizumab $[4,5]$.

In clinical phase III trials, MT with pemetrexed has been shown to improve overall and progression-free survival of patients suffering from non-squamous NSCLC [6-8]. However, MT commits patients to continuous cytotoxic chemotherapy in a disease setting where the overall survival benefit remains modest [3, 9]. Hence, in line with European Society for Medical Oncology guidelines, decision-making about MT must take into account persisting toxicity after first-line chemotherapy, performance status and patients' choices concerning treatment options [10]. In addition to physician ratings, toxicity can be comprehensively evaluated through patient-reported outcome measures (PROMs) such as the assessment of health-related quality of life (HRQOL).

Studies evaluating HRQOL in NSCLC clinical trials showed no substantial impairment of patients' HRQOL following MT with pemetrexed [11-14]. Similar results have been reported for erlotinib $[15,16]$. However, results on HRQOL from clinical trials should be interpreted with caution because of an inherent selection bias whereby patients with low income level or poor health status are less likely to participate in clinical trials, leading to the risk of overestimating HRQOL $[17,18]$.

To enable patients to make an informed decision on whether or not to undergo MT, both patients and physicians require comprehensive data on symptom burden and HRQOL under real-life conditions in this treatment setting [5]. Therefore, further investigation of HRQOL impairments related to pemetrexed MT has been encouraged $[19,20]$, especially in observational studies in a setting which considers the patient's perspective. Therefore, the aim of this study was to assess HRQOL during first-line chemotherapy and subsequent MT, and determine patients' and physicians' reasons leading to clinical decisions in the treatment of advanced NSCLC.

\section{Methods}

\section{Patients}

Patients with advanced NSCLC were consecutively recruited at three Austrian medical centres (Otto-Wagner Hospital in Vienna, Medical University of Innsbruck and Kufstein County Hospital). Patients were eligible at the start of first-line palliative chemotherapy according to the inclusion criteria listed in Table 1.

Sociodemographic and clinical data were collected from the medical charts.

\section{Ethics, consent and permissions}

All participants provided written informed consent. The study was approved by the institutional review boards (Innsbruck Ethics Committee, reference number 4961).

Assessment of patient choices and clinical decision-making Clinical decision-making and patient choice concerning MT were assessed at the end of first-line palliative chemotherapy (T1) and, in the case of subsequent MT, at discontinuation of MT (T2). Both patients and

Table 1 Inclusion and exclusion criteria

\begin{tabular}{ll}
\hline Inclusion criteria & diagnosis of NSCLC (adenocarcinoma or \\
& LC-anaplastic carcinoma) \\
& tumour stage IIIb (wet) or IV \\
& wild-type epidermal growth factor receptor \\
& (EGFR) \\
& first-line therapy with pemetrexed/platin or \\
& vinorelbine/platin \\
& MT with pemetrexed (in the case of remission \\
& or stable disease) or, alternatively, with erlotinib \\
& (only in the case of stable disease) \\
& aged between 18 and 90 years \\
& written informed consent \\
& obvious cognitive impairment \\
Exclusion criteria &
\end{tabular}


physicians were interviewed using a semi-structured interview design with closed and open response formats.

Physicians were asked whether and what kind of MT (pemetrexed or erlotinib) they recommended for a specific patient. Where MT was not recommended, physicians were asked to provide the reason for this decision. Patients were interviewed concerning their decision to undergo MT or not, and the respective reasons for their decision. In the case of discontinuation of MT, the reason was assessed from the patient's as well as the physician's perspective.

\section{Health-related quality of life assessment}

Patients' QOL was assessed at each chemotherapy cycle (including MT) from the initiation of first-line palliative chemotherapy to the start of second-line palliative chemotherapy or at study completion (total of twelve assessment time points).

For HRQOL assessment, the EORTC QLQ-C30 [21] was applied, a widely used questionnaire for the assessment of QOL in cancer patients, and its lung-cancerspecific extension, the EORTC QLQ-LC13 questionnaire module. The EORTC QLQ-C30 covers five functioning domains (physical, role, social, emotional and cognitive), global QOL, eight symptoms (fatigue, pain, nausea/ vomiting, appetite loss, insomnia, dyspnoea, diarrhoea, and constipation) and financial impact of the disease. The recently introduced QLQ-C30 summary score [22] aggregates all scales, except for global QOL and financial impact, into a summary measure of HRQOL.

The lung cancer-specific questionnaire EORTC QLQLC13 [23] assesses dyspnoea, coughing, haemoptysis, sore mouth, dysphagia, peripheral neuropathy, alopecia, chest pain, arm or shoulder pain, and other pain. It was supplemented with questions from the item library of the EORTC QOL Group to assess taste alterations and skin problems [24]. All questionnaire scales were scored $0-100$, with high scores indicating good health status for functioning domains and poor health status for symptom domains.

Questionnaire assessments were performed electronically on tablet computers using the software CHES [25] (ESD, Innsbruck, Austria), which also provided the electronic case report forms used in this study.

\section{Statistical analysis}

Results from the assessment of patient choices and clinical decision-making are provided as relative and absolute frequencies. The answers to open-ended questions were grouped into categories.

The analysis of HRQOL and symptoms was based on mixed linear models with questionnaire scales being the dependent variables and a time and treatment phase variable as fixed factors. In addition, the model included a diagonal covariance structure. Models were estimated separately for each of the questionnaire scales.
Mixed linear models are advantageous for this type of data as they allow the analysis of patients with different numbers of assessments as induced by attrition over time. We compared treatment phases (first-line chemotherapy vs. MT) and change over time within treatment phases using months since the start of treatment phase as the time variable. Since comparisons were only done over time (within-group comparisons) no covariates were included. Results are presented as estimated means and differences with their $95 \%$ confidence intervals.

All statistical analyses were performed using SPSS version 20.0 (IBM Corp. Released 2011. IBM SPSS Statistics for Windows, Version 20.0. Armonk, NY: IBM Corp.).

\section{Results}

\section{Patient characteristics}

Between March 2013 and July 2015, 87 patients were recruited for study inclusion (46 patients at Otto-WagnerHospital, 26 at Medical University of Innsbruck and 15 at Kufstein County Hospital). Three patients changed to a non-study centre during first-line chemotherapy and were excluded from the study. One patient did not provide HRQOL data. Thus, 84 patients were included in the analysis of clinical decision-making and 83 patients were included in the HRQOL analysis. Out of 84 patients, $47(56.0 \%)$ were female. The mean age was 61.6 years (SD 9.8). In total, $27.8 \%$ of patients had undergone previous surgery and $10.1 \%$ had previously received radiation therapy.

Overall, $42.9 \%$ of first-line therapies were based on cisplatin and $44 \%$ on carboplatin $(10.7 \%$ switched from cis- to carboplatin, $1.2 \%$ from carbo- to cisplatin, and $1.2 \%$ were treated with etoposide). The most common first-line chemotherapy regimens were combined pemetrexed and cisplatin (40.5\%) and combined pemetrexed and carboplatin (33.3\%). Nine patients (10.7\%) started on pemetrexed and cisplatin and switched to pemetrexed and carboplatin. Twenty-two patients $(26.2 \%)$ received three cycles or less, 57 patients $(67.9 \%)$ received four cycles and five patients (6.0\%) received five cycles or more. Further details are given in Table 2.

\section{Clinical decision-making and patient choice}

Following first-line chemotherapy, 61 out of 84 patients (73\%) were eligible for MT, whereas 23 patients (27\%) had progressive disease. Among patients with stable disease or partial/complete remission after first-line chemotherapy, 36 (43\%) received MT (33 patients received pemetrexed and 3 received erlotinib). Data on treatment status was unavailable for one patient. Twenty-nine out of 36 patients discontinued MT for reasons given below, while 7 patients were still on MT at study completion. Figure 1 presents the treatment trajectories. 
Table 2 Patient characteristics

\begin{tabular}{|c|c|c|c|}
\hline \multirow[t]{2}{*}{ Age } & \multirow[t]{2}{*}{ Mean (SD) } & \multicolumn{2}{|c|}{$61.6(9.8)$} \\
\hline & & N & $\%$ \\
\hline \multirow[t]{2}{*}{ Sex } & Women & 47 & $56.0 \%$ \\
\hline & Men & 37 & $44.0 \%$ \\
\hline \multirow[t]{3}{*}{ Previous surgery } & Yes & 23 & $27.7 \%$ \\
\hline & No & 60 & $72.3 \%$ \\
\hline & Missing & 1 & \\
\hline \multirow[t]{3}{*}{ Previous radiotherapy } & Yes & 8 & $10.1 \%$ \\
\hline & No & 71 & $89.9 \%$ \\
\hline & Missing & 5 & \\
\hline \multirow[t]{8}{*}{ Regimens (1st line) } & pemetrexed/cisplatin & 34 & $40.5 \%$ \\
\hline & pemetrexed/carboplatin & 28 & $33.3 \%$ \\
\hline & $\begin{array}{l}\text { pemetrexed/ cisplatin } \\
\text { (switch to pemetrexed/ } \\
\text { carboplatin) }\end{array}$ & 9 & $10.7 \%$ \\
\hline & vinorelbine/carboplatin & 7 & $8.3 \%$ \\
\hline & vinorelbine/cisplatin & 2 & $2.4 \%$ \\
\hline & $\begin{array}{l}\text { pemetrexed/carboplatin, } \\
\text { (second vinorelbine/carboplatin) }\end{array}$ & 2 & $2.4 \%$ \\
\hline & $\begin{array}{l}\text { pemetrexed/carboplatin } \\
\text { (reinduction with pemetrexed/ } \\
\text { cisplatin) }\end{array}$ & 1 & $1.2 \%$ \\
\hline & pemetrexed/etoposid & 1 & $1.2 \%$ \\
\hline \multirow[t]{7}{*}{ Cycles } & 1 cycle & 3 & $3.6 \%$ \\
\hline & 2 cycles & 7 & $8.3 \%$ \\
\hline & 3 cycles & 12 & $14.3 \%$ \\
\hline & 4 cycles & 57 & $67.9 \%$ \\
\hline & 5 cycles & 2 & $2.4 \%$ \\
\hline & 6 cycles & 2 & $2.4 \%$ \\
\hline & 8 cycles & 1 & $1.2 \%$ \\
\hline
\end{tabular}

Reasons for not undergoing MT in patients with stable disease or partial/complete response after first-line chemotherapy

Twenty-four patients with stable disease or partial response after first-line chemotherapy did not undergo MT. In most cases (20), the decision was made by the physician, mainly based on toxicity and side effects. Four patients declined MT with pemetrexed (3) or erlotinib (1), despite the physician's recommendation to initiate MT. The main reasons indicated by patients for not opting for MT were the toxicity and side-effects of firstline therapy, the need for a treatment break and physical or emotional exhaustion (Table 3).

\section{Reasons for discontinuation of MT}

Twenty-nine patients undergoing MT discontinued treatment. In the majority of cases (19), the decision not to continue with MT was made by the physician, while the decision was perceived as shared or was a direct decision by the patient in 5 cases, respectively. The main reason for discontinuation according to the physician's decision was tumour progression (18), which resulted in a direct switch to second-line chemotherapy (e.g. docetaxel or erlotinib).

Patients' reasons for not continuing MT included disease progression (indicated by 9 patients), physical and emotional exhaustion (6), need for a treatment break (6), toxicity or side-effects (5) and time constraints (2). Doubts about treatment efficacy, financial burden or the recommendation of family and friends were not reported to have affected the decision for discontinuation.

\section{Health-related quality of life during first-line and maintenance chemotherapy}

We analysed the course of HRQOL across two treatment phases, first-line chemotherapy and MT. Analysis of first-line chemotherapy and MT were based on data from 83 patients, representing 422 assessments in total. Cross-sectional data indicated a statistically significant

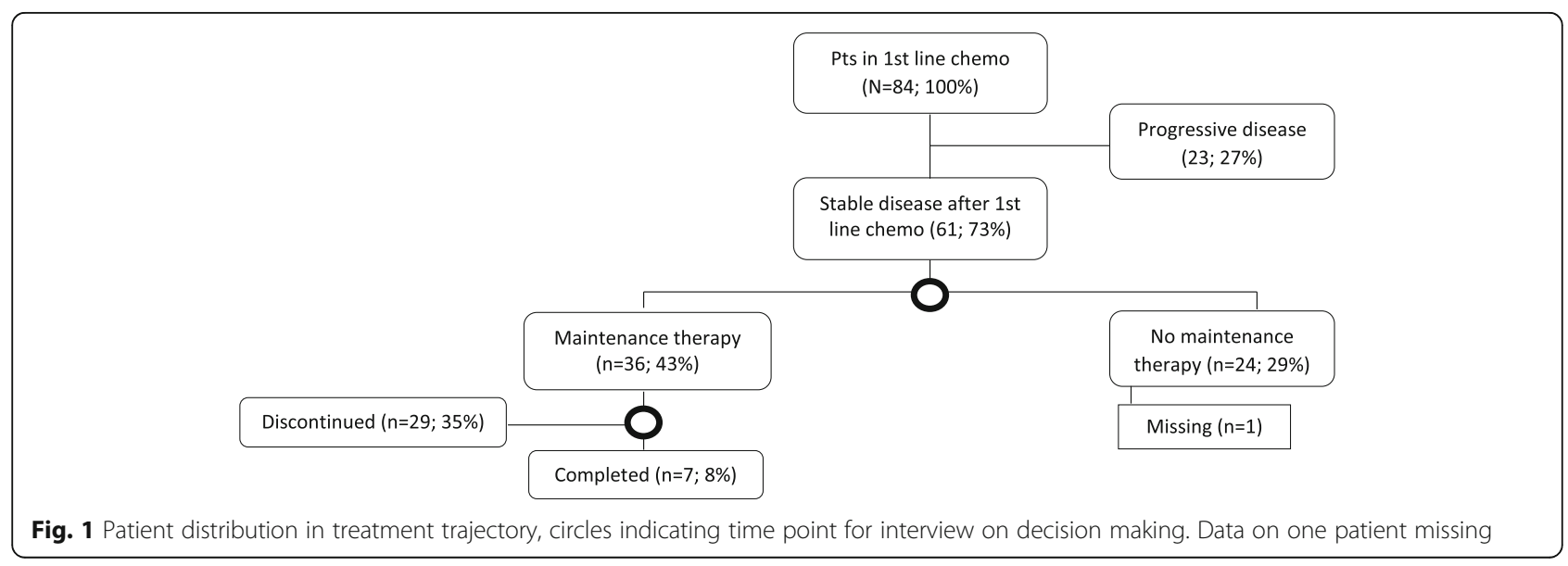


Table 3 Reasons for not undergoing or discontinuing MT (multiple reasons possible)

\begin{tabular}{|c|c|c|c|}
\hline \multicolumn{2}{|l|}{$\begin{array}{l}\text { Reasons for not undergoing } \\
\text { maintenance therapy } \\
(n=24)\end{array}$} & \multicolumn{2}{|l|}{$\begin{array}{l}\text { Reasons for discontinuation of } \\
\text { maintenance therapy } \\
(n=29)\end{array}$} \\
\hline PHYSICIAN & PATIENT & PHYSICIAN & PATIENT \\
\hline Toxicity or side-effects $(n=7)$ & Toxicity or side-effects $(n=14)$ & Disease progression $(n=18)$ & Disease progression $(n=9)$ \\
\hline Regression/ curative treatment $(n=5)$ & Need for treatment break $(n=12)$ & Poor health status $(n=5)$ & $\begin{array}{l}\text { Physical or emotional exhaustion } \\
(n=6)\end{array}$ \\
\hline $\begin{array}{l}\text { Patient wish for treatment holiday } \\
(n=4)\end{array}$ & $\begin{array}{l}\text { Physical or emotional exhaustion } \\
(n=10)\end{array}$ & Treatment toxicity $(n=4)$ & Need for treatment break $(n=6)$ \\
\hline Poor health status $(n=3)$ & $\begin{array}{l}\text { Doubts that treatment would } \\
\text { improve the condition }(n=7)\end{array}$ & $\begin{array}{l}\text { New comorbidities/ metastases } \\
(n=2)\end{array}$ & $\begin{array}{l}\text { Treatment toxicity and side-effects } \\
(n=5)\end{array}$ \\
\hline $\begin{array}{l}\text { Patient compliance, disease } \\
\text { progression ( } n=2 \text { each) }\end{array}$ & Reasons not specified $(n=4)$ & $\begin{array}{l}\text { Remission or deceased } \\
(n=1 \text { each })\end{array}$ & Time burden $(n=2)$ \\
\hline \multirow[t]{3}{*}{$\begin{array}{l}\text { New comorbidity, not eligible } \\
(n=1 \text { each) }\end{array}$} & $\begin{array}{l}\text { Recommendation from family or } \\
\text { friends }(n=3)\end{array}$ & & \\
\hline & $\begin{array}{l}\text { Financial and time burden } \\
(n=2 \text { each) }\end{array}$ & & \\
\hline & $\begin{array}{l}\text { Curative treatment, poor health } \\
\text { status }(n=1 \text { each) }\end{array}$ & & \\
\hline
\end{tabular}

difference on the QLQ-C30 summary score ( $p=0.048$ ) and for specific domains. Lower symptom severity during MT compared with first-line therapy was found for nausea and vomiting (13.5 vs. 8.2 points, $p=0.006$ ), sleep disturbances (39.1 vs. 21.4 points, $p<0.001$ ), appetite loss (26.1 vs. 18.6 points, $p=0.043)$, constipation (17.3 vs. 10.5 points, $p=0.017)$ and chest pain (13.2 vs.
8.0 points, $p=0.022$ ). In contrast, we found higher burden during MT compared with first-line therapy for alopecia (21.7 vs. $10.2, p<0.001)$ and taste alterations (31.4 vs. 19.7, $p=0.004)$. For further details, see Tables 4 and 5 .

Analysis of changes during first-line chemotherapy showed a statistically significant reduction in coughing $(p=0.035)$ and pain in the arm or shoulder $(p=0.023)$.

Table 4 EORTC QLQ-C30 scores during first-line chemotherapy and during MT

\begin{tabular}{|c|c|c|c|c|c|c|c|c|}
\hline & 1st Line & & Mainter & & & & & \\
\hline & Mean & $95 \% \mathrm{Cl}$ & Mean & $95 \% \mathrm{Cl}$ & Diff. & $95 \% \mathrm{Cl}$ & F-value & $p$-value \\
\hline Physical Functioning & 73.5 & $70.7-76.3$ & 73.8 & $69.1-78.6$ & -0.3 & $-5.8-5.2$ & 0.014 & 0.906 \\
\hline Role Functioning & 62.4 & $58.5-66.2$ & 59.1 & $53.0-65.1$ & 3.3 & $-3.9-10.4$ & 0.817 & 0.367 \\
\hline Social Functioning & 66.2 & $62.8-69.7$ & 70.5 & $64.9-76.0$ & -4.2 & $-10.7-2.3$ & 1.630 & 0.203 \\
\hline Emotional Functioning & 65.0 & $62.1-67.9$ & 68.9 & $64.0-73.7$ & -3.9 & $-9.5-1.8$ & 1.826 & 0.178 \\
\hline Cognitive Functioning & 80.0 & $77.4-82.6$ & 82.8 & $78.5-87.1$ & -2.8 & $-7.8-2.2$ & 1.194 & 0.276 \\
\hline Global Quality of Life & 58.2 & $55.7-60.8$ & 57.3 & $53.1-61.4$ & 1.0 & $-3.9-5.8$ & 0.156 & 0.693 \\
\hline Fatigue & 45.8 & $42.4-49.2$ & 41.2 & $35.7-46.8$ & 4.6 & $-1.9-11.1$ & 1.949 & 0.164 \\
\hline NauseaNomiting & 13.5 & $11.0-16.0$ & 8.2 & $5.3-11.1$ & 5.3 & $1.5-9.1$ & 7.663 & 0.006 \\
\hline Pain & 27.0 & $23.6-30.3$ & 24.4 & $18.8-30.0$ & 2.6 & $-3.9-9.1$ & 0.612 & 0.435 \\
\hline Dyspnea & 29.6 & $25.8-33.3$ & 35.9 & $29.9-42.0$ & -6.4 & $-13.4-0.7$ & 3.202 & 0.076 \\
\hline Sleep Disturbances & 39.1 & $35.1-43.2$ & 21.4 & $15.7-27.1$ & 17.8 & $10.8-24.7$ & 25.480 & $<0.001$ \\
\hline Appetite Loss & 26.1 & $22.2-29.9$ & 18.6 & $12.5-24.7$ & 7.5 & $0.2-14.7$ & 4.172 & 0.043 \\
\hline Constipation & 17.3 & 13.9-20.6 & 10.5 & $6.2-14.9$ & 6.7 & $1.2-12.2$ & 5.862 & 0.017 \\
\hline Diarrhea & 7.8 & $5.4-10.3$ & 6.1 & $2.5-9.7$ & 1.7 & $-2.6-6.1$ & 0.627 & 0.430 \\
\hline Financial Impact & 19.6 & $16.3-23.0$ & 23.6 & $17.9-29.3$ & -4.0 & $-10.6-2.6$ & 1.426 & 0.234 \\
\hline QLQ-C30 Summary Score & 71.8 & $69.7-73.9$ & 75.7 & $72.4-79.0$ & -3.9 & $-7.9-0.0$ & 3.948 & 0.048 \\
\hline
\end{tabular}

95\% Cl 95\% confidence interval; Bold type indicates $p<.05$ 
Table 5 EORTC QLQ-LC13 and other symptom scores during first-line chemotherapy and during MT

\begin{tabular}{|c|c|c|c|c|c|c|c|c|}
\hline & 1st Lin & & Mainte & & & & & \\
\hline & Mean & $95 \% \mathrm{Cl}$ & Mean & $95 \% \mathrm{Cl}$ & Diff. & $95 \% \mathrm{Cl}$ & F-value & $p$-value \\
\hline Dyspnoea & 23.0 & $19.9-26.0$ & 21.2 & $0.0-45.4$ & 1.73 & $-22.6-26.1$ & 0.230 & 0.632 \\
\hline Coughing & 31.1 & $27.8-34.4$ & 26.7 & $21.4-32.0$ & 4.4 & $-1.8-10.6$ & 1.943 & 0.165 \\
\hline Haemoptysis & 2.8 & $1.1-4.5$ & $<0.1$ & $0.0-10.5$ & 2.8 & $-7.8-13.4$ & 0.273 & 0.603 \\
\hline Sore mouth & 8.0 & $5.5-10.4$ & 7.0 & $2.9-11.1$ & 1.0 & $-3.7-5.8$ & 0.183 & 0.670 \\
\hline Dysphagia & 9.1 & $6.8-11.4$ & 6.1 & $1.7-10.6$ & 3.0 & $-2.0-8.0$ & 1.408 & 0.237 \\
\hline Peripheral neuropathy & 14.9 & $11.8-18.0$ & 18.8 & $13.7-23.9$ & -3.9 & $-9.9-2.0$ & 1.711 & 0.192 \\
\hline Alopecia & 10.2 & 7.3-13.0 & 21.7 & $16.6-26.8$ & -11.5 & $-17.4--5.7$ & 15.116 & $<0.001$ \\
\hline Pain in chest & 13.2 & $10.8-15.7$ & 8.0 & $4.3-11.7$ & 5.3 & $0.8-9.7$ & 5.437 & 0.022 \\
\hline Pain in arm or shoulder & 18.1 & $14.8-21.3$ & 19.6 & $14.6-24.7$ & -1.6 & $-7.6-4.4$ & 0.266 & 0.607 \\
\hline Pain in other parts & 24.9 & $21.0-28.9$ & 25.2 & $18.3-32.0$ & -0.2 & $-8.1-7.6$ & 0.004 & 0.951 \\
\hline Taste Alterations $^{\mathrm{a}}$ & 19.7 & $16.1-23.2$ & 31.4 & $24.3-38.4$ & -11.7 & $-19.6--3.7$ & 8.442 & 0.004 \\
\hline Skin Toxicity ${ }^{a}$ & 18.1 & $15.0-21.3$ & 16.9 & $12.0-21.8$ & 1.2 & $-4.6-7.0$ & 0.179 & 0.673 \\
\hline
\end{tabular}

95\% Cl 95\% confidence interval; Bold type indicates $p<.05$

aitems from the EORTC item bank

In contrast, nausea and vomiting $(p=0.012)$, constipation $(p=0.003)$ and alopecia $(p<0.001)$ increased throughout first-line chemotherapy. During MT, emotional functioning $(p=0.023)$ and cognitive functioning $(p=0.044)$ deteriorated and appetite loss $(p=0.001)$, constipation $(p=0.003)$ and financial impact $(p=0.041)$ increased. Nausea and vomiting improved over time $(p<0.001)$, given the discontinuation of platin-based chemotherapy in MT. As a result of attrition, the longitudinal analysis only covered the first 4 months of each treatment phase, with later time points being excluded.

\section{Discussion}

This study aimed at assessing clinical decision-making for MT with either pemetrexed or erlotinib as well as HRQOL in patients with advanced NSCLC in a real-world setting. Compared with first-line therapy, we found that the HRQOL and symptom burden improved in MT for symptoms such as nausea and vomiting, sleep disturbances, constipation and appetite loss. While this may be partly explained by the discontinuation of platin-based chemotherapy, the reported increase in alopecia and taste alterations might possibly indicate late first-line treatment toxicity.

Our findings are comparable to those of studies reporting on HRQOL in maintenance pemetrexed [11-13] showing that HRQOL seems to be at least maintained during long-term MT for certain symptoms while further impairing others. When compared with patients receiving placebo, patients undergoing MT with both pemetrexed [13] and erlotinib [15] reported similar HRQOL using the self-administered Functional Assessment of Cancer Therapy-Lung (FACT-L), with the exception of a larger degree of appetite loss under MT as well a significantly prolonged time to worsening of pain and analgesic use.

In the landmark PARAMOUNT trial [14], pemetrexed was associated with significantly more low-grade nausea, anaemia, oedema, and neutropenia than placebo, while the incidence of low-grade fatigue, anaemia, and neutropenia decreased with longer treatment exposure. Though HRQOL impairments in the course of longterm pemetrexed maintenance as measured by the EQ$5 \mathrm{D}$ were not substantial, even low-grade toxicities were reported to have been potentially burdensome for patients.

In our study, treatment toxicity and side effects as well as physical and emotional exhaustion were the most common reasons for patients to decline MT in the first place. The reported incidence of reasons, however, might imply that clinicians underestimate the effects of patient-reported toxicity and treatment sequelae. Treatment toxicity and side effects of first-line chemotherapy were indicated twice as often by patients than by physicians to be the reason for not considering MT, despite stable disease. Patients further reported physical or emotional exhaustion in 10 cases. This finding is consistent with other treatment preference studies [26] where the extent and severity of current treatment-related side effects played a large role in patients' attitudes to continued treatment. While patients attach high value to delaying the worsening of symptoms [27], progressionfree survival benefits are viewed as most beneficial when disease symptoms are mild but as detrimental when disease symptoms are severe [28].

This discrepancy in patients' and physicians' perceptions of treatment burden and reasoning for and against MT reflects the notion that information reported by the 
physician cannot substitute direct patient reporting [29]. In this study, the physician voiced the decision to opt for or discontinue MT in the majority of cases. This emphasises the need for closer integration of PROMs such as the assessment of HRQOL and patient choice of treatment into the process of clinical decision-making on MT. Systematic collection of patient-reported outcome data in the real-world clinical setting has proven feasible and can contribute to clinical management on different levels [30-32]. Group-level data on HRQOL during MT provide patients and clinicians with information to substantiate possible treatment-related functional and HRQOL consequences, thereby promoting shared and informed decision-making. On the individual patient level, continuous PROM monitoring supports personalised clinical management, enhancing patient-physician communication and continuity of care [33, 34].

The interpretation of our results is limited by the fact that while addressing first-line chemotherapy and MT, the study excluded second-line treatment as well as patients who did not receive MT after first-line chemotherapy. The latter, in particular, would have represented an interesting comparator group but were not assessable for logistical reasons. Because of the study sample size, particularly during MT, statistical power allowed only limited analyses of change over time. Belani et al. [13] reported similar problems regarding compliance with questionnaire completion in the PARAMOUNT trial. Despite the study limitations, however, the comprehensive assessment of HRQOL and symptom burden using the EORTC QLQ-C30, its lung cancer-specific modules QLQ-LC13, and additional items on taste alterations and skin toxicity are strengths of this study.

\section{Conclusions}

Our results indicate that HRQOL and symptom burden during MT stabilise over time in some aspects, while remaining debilitating in others. Treatment burden dominates patients' perspectives on therapy and affects their treatment decisions. Comprehensive data on symptom burden and HRQOL impact of MT systematically assessed under real-life conditions can contribute to optimised clinical care. As the use of MT is increasingly considered in other advanced cancers [35, 36], the integration of PROMs generated in clinical trials as well as on the individual patient level is required to enable shared decision-making and personalised health care based on a mutual understanding of treatment objectives and expectations.

\footnotetext{
Abbreviations

EORTC QLQ-C30: European Organisation of Research and Treatment of Cancer Quality of Life Questionnaire Core 30; EORTC QLQ-LC13: European Organisation of Research and Treatment of Cancer Quality of Life
}

Questionnaire Lung Cancer 13; FACT-L: Functional Assessment of Cancer Therapy-Lung; HRQOL: Health-related quality of life; MT: Maintenance therapy; NSCLC: Non-squamous non-small cell lung cancer; PROM: Patientreported outcome measure

\section{Acknowledgements}

Our thanks to the student co-workers supporting data collection: Maren Kammler, Öyküm Nazik, Martin Kotynski, and Florian Schober.

\section{Funding}

This study was financially supported by Eli Lilly and Company. Eli Lilly did not have any role in the design of the study, analysis and interpretation of data nor in writing the manuscript. The funding mainly contributed to the cost of data collection and follow-up of the patients in this study.

\section{Availability of data and materials}

The datasets used and analysed during the current study are available from the corresponding author on reasonable request and with permission of the co-authors.

\section{Authors' contributions}

The current study was designed by JMG, AZ, EK, GP, WH, OB, MH and BH. Acquisition of data was organised by $A Z, E K, G P, W H, O B, M H, B H, G R$ and SD. JMG, MS and BH performed the statistical analysis. MS, JMG, AZ, GP, SD and $\mathrm{BH}$ interpreted the data. All authors have been involved in drafting or revising the manuscript and have read and approved the final version.

\section{Ethics approval and consent to participate}

This study was approved by the Ethics Committee of the Medical University of Innsbruck, Austria (reference number 4961). All procedures followed were in accordance with the ethical standards of the responsible committee on human experimentation (institutional and national) and with the Helsinki Declaration of 1964 and later versions. All patients provided written informed consent.

\section{Consent for publication}

Not applicable.

\section{Competing interests}

Bernhard Holzner is an owner of the intellectual property rights of the software CHES. None of the other authors has a conflict of interest to declare.

\section{Publisher's Note}

Springer Nature remains neutral with regard to jurisdictional claims in published maps and institutional affiliations.

\section{Author details}

${ }^{1}$ Department of Psychiatry, Psychotherapy \& Psychosomatics, Medical University of Innsbruck, Innsbruck, Austria. ${ }^{2}$ Leopold-Franzens-University of Innsbruck, Innsbruck, Austria. ${ }^{3}$ Department of Internal Medicine, Kufstein County Hospital, Kufstein, Austria. ${ }^{4}$ Waldburg-Zeil Akutkliniken GmbH \& Co. KG, Wangen, Germany. ${ }^{5}$ Department of Internal Medicine I (Haematology and Oncology), Wilhelminenspital Wien, Vienna, Austria. ${ }^{6}$ Respiratory Oncology Unit, Department of Respiratory and Critical Care Medicine, Otto-Wagner-Spital, Vienna, Austria. ${ }^{7}$ Department of Psychoanalysis and Psychotherapy, Medical University of Vienna, Vienna, Austria.

Received: 4 April 2017 Accepted: 14 August 2017

Published online: 23 August 2017

\section{References}

1. Jemal A, Bray F, Center MM, Ferlay J, Ward E, Forman D. Global cancer statistics. CA Cancer J Clin. 2011;61:69-90.

2. Ettinger DS, Wood DE, Akerley W, Bazhenova LA, Borghaei H, Camidge DR, Cheney RT, Chirieac LR, D'Amico TA, Dilling TJ, Dobelbower MC, Govindan R, Hennon M, Horn L, Jahan TM, Komaki R, Lackner RP, Lanuti M, Lilenbaum R, Lin J, Loo BW Jr, Martins R, Otterson GA, Patel JD, Pisters KM, Reckamp K, Riely GJ, Schild SE, Shapiro TA, Sharma N, Stevenson J, Swanson SJ, Tauer K, Yang SC, Gregory K, Hughes M. NCCN guidelines insights: non-small cell lung cancer, version 4.2016. J Natl Compr Cancer Netw. 2016;14:255-64. 
3. Berge EM, Doebele RC. Re-examination of maintenance therapy in nonsmall cell lung cancer with the advent of new anti-cancer agents. Drugs. 2013;73:517-32.

4. Pennell NA. Selection of chemotherapy for patients with advanced non-small cell lung cancer. Cleve Clin J Med. 2012;79(Electronic Suppl 1):eS46-50.

5. Gerber DE, Schiller JH. Maintenance chemotherapy for advanced non-smallcell lung cancer: new life for an old idea. J Clin Oncol. 2013;31:1009-20.

6. Treat J, Scagliotti GV, Peng G, Monberg MJ, Obasaju CK, Socinski MA Comparison of pemetrexed plus cisplatin with other first-line doublets in advanced non-small cell lung cancer (NSCLC): a combined analysis of three phase 3 trials. Lung Cancer. 2012;76:222-7.

7. Kulkarni S, Vella ET, Coakley N, Cheng S, Gregg R, Ung YC, Ellis PM. The use of systemic treatment in the maintenance of patients with non-small cell lung cancer: a systematic review. J Thorac Oncol. 2016;11:989-1002.

8. Mubarak N, Gaafar R, Shehata S, Hashem T, Abigeres D, Azim HA, ElHusseiny G, Al-Husaini H, Liu Z. A randomized, phase 2 study comparing pemetrexed plus best supportive care versus best supportive care as maintenance therapy after first-line treatment with pemetrexed and cisplatin for advanced, non-squamous, non-small cell lung cancer. BMC Cancer. 2012;12:423.

9. Gentzler RD, Patel JD. Maintenance treatment after induction therapy in non-small cell lung cancer: latest evidence and clinical implications. Ther Adv Med Oncol. 2014;6:4-15.

10. Reck M, Popat S, Reinmuth N, De Ruysscher D, Kerr KM, Peters S. Metastatic non-small-cell lung cancer (NSCLC): ESMO clinical practice guidelines for diagnosis, treatment and follow-up. Ann Oncol. 2014;25(Suppl 3):iii27-39.

11. Paz-Ares L, de Marinis F, Dediu M, Thomas M, Pujol JL, Bidoli P, Molinier O, Sahoo TP, Laack E, Reck M, Corral J, Melemed S, John W, Chouaki N, Zimmermann AH, Visseren-Grul C, Gridelli C. Maintenance therapy with pemetrexed plus best supportive care versus placebo plus best supportive care after induction therapy with pemetrexed plus cisplatin for advanced non-squamous non-small-cell lung cancer (PARAMOUNT): a double-blind, phase 3, randomised controlled trial. Lancet Oncol. 2012;13:247-55.

12. Ciuleanu T, Brodowicz T, Zielinski C, Kim JH, Krzakowski M, Laack E, Wu YL, Bover I, Begbie S, Tzekova V, Cucevic B, Pereira JR, Yang SH, Madhavan J, Sugarman KP, Peterson P, John WJ, Krejcy K, Belani CP. Maintenance pemetrexed plus best supportive care versus placebo plus best supportive care for non-small-cell lung cancer: a randomised, double-blind, phase 3 study. Lancet. 2009;374:1432-40.

13. Belani CP, Brodowicz T, Ciuleanu TE, Krzakowski M, Yang SH, Franke F, Cucevic B, Madhavan J, Santoro A, Ramlau R, Liepa AM, Visseren-Grul C, Peterson P, John WJ, Zielinski CC. Quality of life in patients with advanced non-small-cell lung cancer given maintenance treatment with pemetrexed versus placebo (H3E-MC-JMEN): results from a randomised, double-blind, phase 3 study. Lancet Oncol. 2012:13:292-9.

14. Pujol JL, Paz-Ares L, de Marinis F, Dediu M, Thomas M, Bidoli P, Corral J, San Antonio B, Chouaki N, John W, Zimmermann A, Visseren-Grul C, Gridelli C. Long-term and low-grade safety results of a phase III study (PARAMOUNT) maintenance pemetrexed plus best supportive care versus placebo plus best supportive care immediately after induction treatment with pemetrexed plus cisplatin for advanced nonsquamous non-small-cell lung cancer. Clin Lung Cancer. 2014;15:418-25.

15. Juhasz $\mathrm{E}, \mathrm{Kim} J \mathrm{H}$, Klingelschmitt $\mathrm{G}$, Walzer S. Effects of erlotinib first-line maintenance therapy versus placebo on the health-related quality of life of patients with metastatic non-small-cell lung cancer. Eur J Cancer. 2013:49:1205-15.

16. Coudert B, Ciuleanu T, Park K, Wu YL, Giaccone G, Brugger W, Gopalakrishna $P$, Cappuzzo F. Survival benefit with erlotinib maintenance therapy in patients with advanced non-small-cell lung cancer (NSCLC) according to response to first-line chemotherapy. Ann Oncol. 2012;23:388-94.

17. Unger JM, Hershman DL, Albain KS, Moinpour CM, Petersen JA, Burg K, Crowley JJ. Patient income level and cancer clinical trial participation. J Clin Oncol. 2013;31:536-42.

18. Rothwell PM. Factors that can affect the external validity of randomised controlled trials. PLoS Clin Trials. 2006;1:e9.

19. Cella DF, Patel JD. Improving health-related quality of life in non-small-cell lung cancer with current treatment options. Clin Lung Cancer. 2008;9:206-12.

20. Stinchcombe TE, Cella D. Does maintenance pemetrexed maintain quality of life? Lancet Oncol. 2012;13:224-5.

21. Aaronson NK, Ahmedzai S, Bergman B, Bullinger M, Cull A, Duez NJ, Filiberti A, Flechtner H, Fleishman SB, de Haes JC, et al. The European Organization for
Research and Treatment of cancer QLQ-C30: a quality-of-life instrument for use in international clinical trials in oncology. J Natl Cancer Inst. 1993:85:365-76.

22. Giesinger JM, Kieffer JM, Fayers PM, Groenvold M, Petersen MA, Scott NW, Sprangers MA, Velikova G, Aaronson NK. Replication and validation of higher order models demonstrated that a summary score for the EORTC QLQ-C30 is robust. J Clin Epidemiol. 2016;69:79-88.

23. Bergman B, Aaronson NK, Ahmedzai S, Kaasa S, Sullivan M. The EORTC QLQLC13: a modular supplement to the EORTC Core quality of life questionnaire (QLQ-C30) for use in lung cancer clinical trials. EORTC study group on quality of life. Eur J Cancer. 1994;30A:635-42.

24. Group EQoL. Item Library In.

25. Holzner B, Giesinger JM, Pinggera J, Zugal S, Schopf F, Oberguggenberger AS, Gamper EM, Zabernigg A, Weber B, Rumpold G. The computer-based health evaluation software (CHES): a software for electronic patient-reported outcome monitoring. BMC Med Inform Decis Mak. 2012;12:126.

26. Gerber DE, Hamann HA, Rasco DW, Woodruff S, Lee SJ. Patient comprehension and attitudes toward maintenance chemotherapy for lung cancer. Patient Educ Couns. 2012;89:102-8.

27. Peeters L, Sibille A, Anrys B, Oyen C, Dooms C, Nackaerts K, Wauters I, Vansteenkiste J. Maintenance therapy for advanced non-small-cell lung cancer: a pilot study on patients' perceptions. J Thorac Oncol. 2012;7:1291-5.

28. Bridges JF, Mohamed AF, Finnern HW, Woehl A, Hauber AB. Patients' preferences for treatment outcomes for advanced non-small cell lung cancer: a conjoint analysis. Lung Cancer. 2012;77:224-31.

29. Basch $E$. The missing voice of patients in drug-safety reporting. $\mathrm{N}$ Engl Med. 2010;362:865-9.

30. Macefield RC, Avery KN, Blazeby JM. Integration of clinical and patientreported outcomes in surgical oncology. Br J Surg. 2013;100:28-37.

31. Snyder CF, Blackford AL, Wolff AC, Carducci MA, Herman JM, Wu AW. Feasibility and value of PatientViewpoint: a web system for patient-reported outcomes assessment in clinical practice. Psychooncology. 2013;22:895-901.

32. Gamper EM, Wintner LM, Rodrigues M, Buxbaum S, Nilica B, Singer S, Giesinger JM, Holzner B, Virgolini I. Persistent quality of life impairments in differentiated thyroid cancer patients: results from a monitoring programme. Eur J Nucl Med Mol Imaging. 2015:42:1179-88.

33. Velikova G, Booth L, Smith AB, Brown PM, Lynch P, Brown JM, Selby PJ. Measuring quality of life in routine oncology practice improves communication and patient well-being: a randomized controlled trial. J Clin Oncol. 2004;22:714-24.

34. Velikova G, Keding A, Harley C, Cocks K, Booth L, Smith AB, Wright P, Selby PJ, Brown JM. Patients report improvements in continuity of care when quality of life assessments are used routinely in oncology practice: secondary outcomes of a randomised controlled trial. Eur J Cancer. 2010;46: 2381-8.

35. Haines I. Rituximab maintenance therapy for follicular lymphoma. Lancet. 2011:377:1151. author reply 1151-1152

36. Murphy CG, Khasraw M, Seidman AD. Holding back the sea: the role for maintenance chemotherapy in metastatic breast cancer. Breast Cancer Res Treat. 2010;122:177-9.

\section{Submit your next manuscript to BioMed Central and we will help you at every step:}

- We accept pre-submission inquiries

- Our selector tool helps you to find the most relevant journal

- We provide round the clock customer support

- Convenient online submission

- Thorough peer review

- Inclusion in PubMed and all major indexing services

- Maximum visibility for your research

Submit your manuscript at www.biomedcentral.com/submit
) Biomed Central 